\title{
ANTINOCICEPTIVE ACTION OF ONONIS SPINOSA LEAF EXTRACT IN MOUSE PAIN MODELS
}

\author{
SAHAR MAJDI JAFFAL and MANAL AHMAD ABBAS*
}

\author{
Faculty of Pharmacy and Medical Sciences, Al-Ahliyya Amman University, \\ 19328, Amman, Jordan
}

\begin{abstract}
Ononis spinosa (spiny restharrow) is a perennial herb that belongs to the Fabaceae family. Among several uses, the aerial parts of $O$. spinosa are used in traditional medicine for toothache. In this study, analgesic activity of the methanolic extract of leaves was studied. In writhing test, the $300 \mathrm{mg} / \mathrm{kg}$ and $600 \mathrm{mg} / \mathrm{kg}$ doses of $O$. spinosa extract produced $90.1 \%$ and $94.5 \%$ inhibition of abdominal cramps, respectively compared to $23.6 \%$ inhibition produced by $30 \mathrm{mg} / \mathrm{kg}$ diclofenac sodium. $O$. spinosa methanolic extract reduced the time of licking in early and late phases of the formalin test. The inhibitory effect of $O$. spinosa extract was more pronounced in late phase. The lowest dose tested $(300 \mathrm{mg} / \mathrm{kg}$ ) of $O$. spinos $a$ extract produced $81.0 \%$ inhibition compared to $50.5 \%$ inhibition in $30 \mathrm{mg} / \mathrm{kg}$ diclofenac sodium in the late phase of the formalin test. This effect was not abrogated by glibenclamide, naloxone or atropine indicating that the action of $O$. spinosa in formalin test is not mediated by ATP-sensitive $\mathrm{K}^{+}$channel, opioid or muscarinic receptors. In tail-flick and hot-plate tests, $O$. spinosa increased the latency time at $30 \mathrm{~min}$ and $150 \mathrm{~min}$. Naloxone antagonized the action of $O$. spin$o s a$ in both tests suggesting an interaction with the opioid receptor as a possible mechanism of $O$. spinosa in thermal pain models at the spinal and supraspinal levels. Phytochemical screening indicated the presence of phenolics, saponins, flavonoids, and terpenoids. Alkaloids, sterols, and anthraquinone glycosides were absent. HPLC analysis confirmed the presence of kaempferol, apigenin and myricetin in the extract.
\end{abstract}

Keywords: Ononis spinosa, analgesic activity, opioid receptor

Ononis spinosa (spiny restharrow) is a perennial herb that belongs to the family Fabaceae with many non-sticky hanging stems, trifoliate serrate leaflets and pink-violet flowers (1). This plant is widespread in the Mediterranean region of Europe, in West Asia and North Africa (2, 3). O. spinosa is used for treating kidney stones and inflammatory diseases (4) and healing wounds (5). In fact, ononidis radix; the dried roots of $O$. spinosa are commercially available in different forms for various uses. The herbal tea of this plant is taken mainly as a diuretic and for rheumatism (3).

Among several uses, the aerial parts of $O$. spinosa are used in traditional medicine for toothache (6) and the flowers for abdominal pain (7). Analgesic activity of the aerial parts of this plant was reported earlier using writhing test and tail flick test (4). However, it has not been studied in other pain models. Therefore, this study was performed to investigate the effect of $O$. spinosa in the formalin test and to examine its mechanism of action.

\section{MATERIALS AND METHODS}

\section{Drugs}

Atropine was purchased from Sigma-Aldrich (USA), diclofenac sodium was from Novartis (Switzerland), glibenclamide (Glibil) was obtained from Hikma Pharmaceuticals (Jordan) and naloxone hydrochloride was purchased from Tocris Bioscience (UK). All drugs were dissolved in sterile normal saline and administered intraperitoneally (i.p).

\section{Collection of plant material}

$O$. spinosa was collected from Subaihi, Jordan in July 2016. The plant was authenticated by Prof. Barakat Abu-Irmaileh/The University of Jordan. A voucher specimen was deposited in the Graduate Studies Laboratory at Al-Ahliyya Amman University.

\section{Preparation of plant extract}

Leaves of $O$. spinosa were dried at room temperature away from sunlight. Methanolic extract of

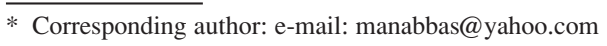


the leaves was prepared by maceration in $96 \%$ methanol (Scharlau chemicals, Spain) for 3 days. Rotary evaporator was used to evaporate methanol under reduced pressure at a temperature not exceeding $45^{\circ} \mathrm{C}$. The extract was stored at $-20^{\circ} \mathrm{C}$ and was dissolved in sterile normal saline immediately before use. $O$. spinosa extract was administered i.p to the animals in all tests performed.

\section{Experimental animals}

All followed procedures comply with the Jordanian Animal Welfare By-Law No. (11) of the year 2010 and the International Association for the Study of Pain (IASP) Guidelines for the Use of Animals in Research and were approved by the ethical committee for research on animals at AlAhliyya Amman University. Male BALB/c mice (weight: 20-25 g) were used in all experiments. Mice were brought from the animal house at AlAhliyya Amman University, Jordan. Animals were kept at $23 \pm 2^{\circ} \mathrm{C}$ with $12 \mathrm{~h}$ lightness and $12 \mathrm{~h}$ darkness. Water and pellets of food were available $a d$ libitum. Before tests, the animals were acclimatized to the experimental room for at least $120 \mathrm{~min}$.

\section{Writhing test}

The writhing test was performed by injecting acetic acid solution $(1 \%, 10 \mathrm{~mL} / \mathrm{kg}$, i.p) $30 \mathrm{~min}$ after receiving the vehicle, $O$. spinosa extract $(300 \mathrm{mg} / \mathrm{kg}$ or $600 \mathrm{mg} / \mathrm{kg}$ ) or $30 \mathrm{mg} / \mathrm{kg}$ diclofenac sodium. Each group consisted of 8 mice. The animals were then placed in transparent cages. Ten minutes after acetic acid injection, the number of writhes was counted for $20 \mathrm{~min}$. Writhe was defined as a contraction of the abdominal muscles with elongation of the body and extension of the forelimbs. The percentage inhibition of abdominal cramps was calculated using this formula:

\section{Paw licking test}

Animals were divided randomly into groups of 9 mice each. Paw licking test was carried out by injecting twenty microliters of formalin (2.5\%) intraplantarly to the left hind paw of the animal. Nociception was determined by counting the time of licking the injected paw, moving while lifting the leg or exhibiting flinching behavior. Counting was performed during the first $5 \mathrm{~min}$ after formalin injection (early phase) and during the late phase (25-30 $\mathrm{min})$. The percentage inhibition was calculated using this formula:

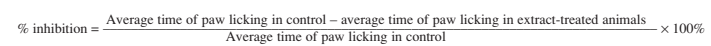

Animals were pretreated i.p with vehicle (sterile normal saline, control), O. spinosa methanolic extract (300 or $600 \mathrm{mg} / \mathrm{kg}$ ) or $30 \mathrm{mg} / \mathrm{kg}$ diclofenac sodium (standard drug) $30 \mathrm{~min}$ prior to performing the experiments. Naloxone $(5 \mathrm{mg} / \mathrm{kg})$ or glibenclamide $(10 \mathrm{mg} / \mathrm{kg})$ were injected $30 \mathrm{~min}$ before a fixed dose of $O$. spinosa extract $(300 \mathrm{mg} / \mathrm{kg}$ or 600 $\mathrm{mg} / \mathrm{kg}$ ). Atropine $(5 \mathrm{mg} / \mathrm{kg})$ was administered 15 min before extract.

\section{Hot-plate test}

Animals were divided randomly into 7 groups of 13 mice each. The hot-plate test was used to determine the latencies in pain reaction at $30 \mathrm{~min}$ and $150 \mathrm{~min}$. The test was fulfilled only once for every mouse. The animal reaction was assessed by placing the mouse in a glass beaker on a hot-plate at $55 \pm 1^{\circ} \mathrm{C}$. The time between the animal's placement and first jumping was recorded as an indication for the latency of pain reaction. A cutoff time of $60 \mathrm{sec}$ was determined to avoid tissue damage.

\section{Tail-flick test}

Animals were divided randomly into 7 groups of 13 mice each. The tail-flick test was done by immersing the tail in water at $55 \pm 1{ }^{\circ} \mathrm{C}$. The time starting from immersing the tail in water till showing the first flick was measured after $30 \mathrm{~min}$ and 150 min of plant extract administration. A cutoff time of $10 \mathrm{sec}$ was determined.

\section{Qualitative analysis of phytochemicals in O. spinosa}

For the identification of the main phytochemical groups in $O$. spinosa the following tests were performed as in (8) namely: For alkaloids Dragendorff's test, for phenolics ferric chloride test, for sterols and triterpenes Salkowski test. Flavonoid presence was confirmed by positive alkaline reagent and ferric chloride tests. The presence of anthraquinone glycosides was tested by the addition of ammonia. Saponin presence was checked by shaking the extract vigorously, persistence of foam for $5 \mathrm{~min}$ is indicative of saponin presence.

\section{HPLC analysis of $O$. spinosa methanolic leaf extract}

The analysis of plant extract was performed using HPLC system Merck-Hitachi equipped with gradient pump L7150, auto sampler L7200, diode array detector L7450. The mobile phase consisted of two mixtures delivered to a reversed phase column $(\mathrm{C} 18 \mathrm{KYA} 250 \mathrm{~mm} \times 4.6 \mathrm{~mm}$ ) in gradient mode, mobile phase A consisted of $95: 5$ phosphate buffer 
pH 3.3 to acetonitrile and mobile phase B consisted of $30: 70$ phosphate buffer to acetonitrile. Monitoring wavelength was at $250 \mathrm{~nm}$. Mobile A from 0 to 3 minutes $100 \%$ and mobile B $0 \%$ at a flow rate of $1.2 \mathrm{~mL} / \mathrm{min}$. Mobile A from 3 to 24 minutes $0 \%$ and mobile B $100 \%$ at a flow rate of $1.2 \mathrm{~mL} / \mathrm{min}$. The aim of using diode array detection is to monitor, $\mathrm{UV}$

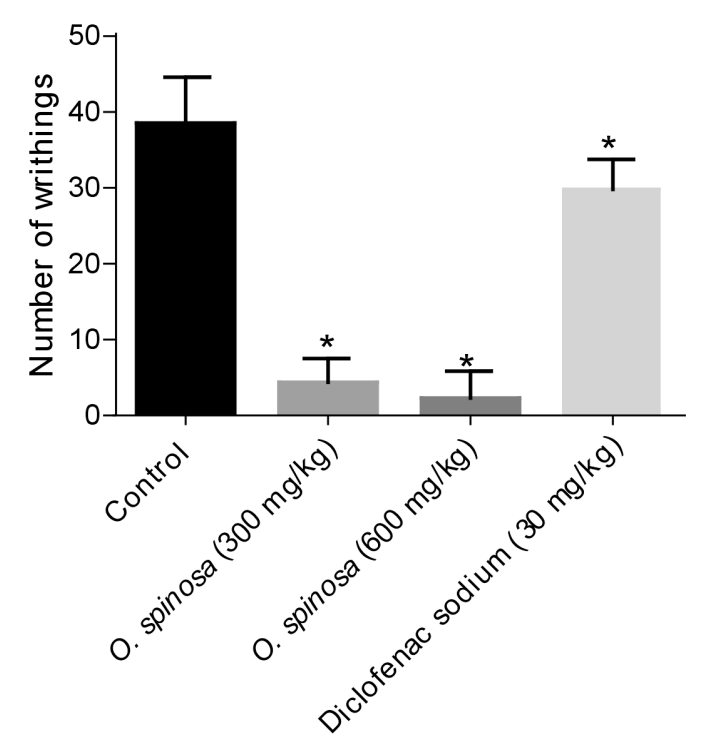

Figure 1. Results of the acetic acid-induced writhing test * Significant difference from the control $(\mathrm{p}<0.05)$ spectrum of each peak that could help in confirming that it refers to the corresponding standard.

\section{Statistical analysis}

Statistical significance of differences between groups was assessed using one-way analysis of variance (ANOVA) followed by Tukey's post-hoc test. GraphPad Prism version 6 was chosen to perform the statistical analysis. Results were represented as the mean \pm standard error of the mean (SEM).

\section{RESULTS}

\section{Writhing test}

Both doses of $O$. spinosa (300 and $600 \mathrm{mg} / \mathrm{kg}$ ) decreased the number of writhings in a significant manner compared to the vehicle-treated group (Fig. 1). The i.p administration of $300 \mathrm{mg} / \mathrm{kg}$ and 600 $\mathrm{mg} / \mathrm{kg}$ dose of $O$. spinosa extract resulted in $90.1 \%$ and $94.5 \%$ inhibition of abdominal cramps, respectively while diclofenac sodium $(30 \mathrm{mg} / \mathrm{kg})$ produced only $23.6 \%$ inhibition.

\section{Paw licking test}

Both doses of $O$. spinosa (300 and $600 \mathrm{mg} / \mathrm{kg}$ ) inhibited significantly paw licking in the early phase of the formalin test (Fig. 2A). Percentage inhibition in the early phase was $54.9 \%, 63.1 \%$, and $50.5 \%$ for the low dose $(300 \mathrm{mg} / \mathrm{kg})$, high dose $(600 \mathrm{mg} / \mathrm{kg})$ of $O$. spinosa and diclofenac sodium $(30 \mathrm{mg} / \mathrm{kg})$, respectively. Also, in the late phase, both doses of

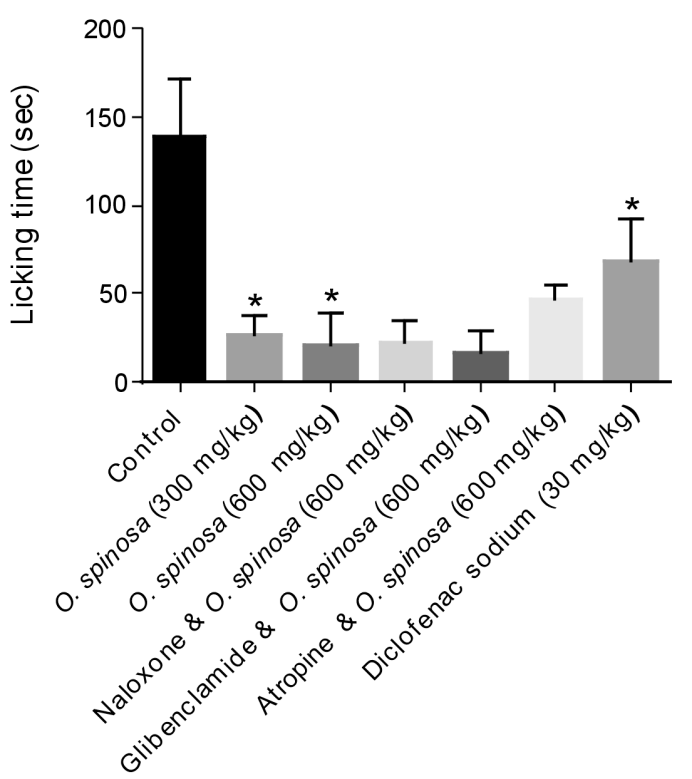

Figure 2. Results of paw-licking test. (A) Early phase (B) Late phase of formalin test * Significant difference from the control $(p<0.05)$ 
O. spinosa produced significant inhibition (Fig. 2B). The percentage inhibition was $81.0 \%, 85.3 \%$ and $50.5 \%$ for low dose $(300 \mathrm{mg} / \mathrm{kg})$, high dose $(600$ $\mathrm{mg} / \mathrm{kg}$ ) of $O$. spinosa and diclofenac sodium (30 $\mathrm{mg} / \mathrm{kg}$ ), respectively. The effect of $O$. spinosa was not abrogated by glibenclamide, naloxone or atropine in any of the 2 phases (Fig. 2).
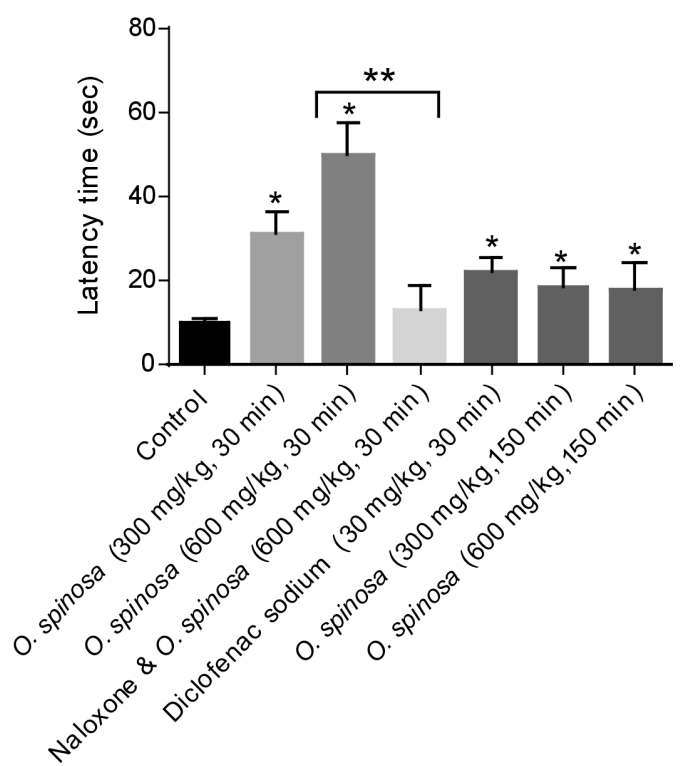

(A)

Figure 3. Effect of $O$. spinosa extract in thermal pain models (A) Hot-plate test. (B) Tail-flick test * Significant difference from the control $(\mathrm{p}<0.05)$.

** Significant difference between $O$. spinosa $(600 \mathrm{mg} / \mathrm{kg})$ and $O$. spinosa $(600 \mathrm{mg} / \mathrm{kg})$ pretreated with naloxone $(\mathrm{p}<0.05)$

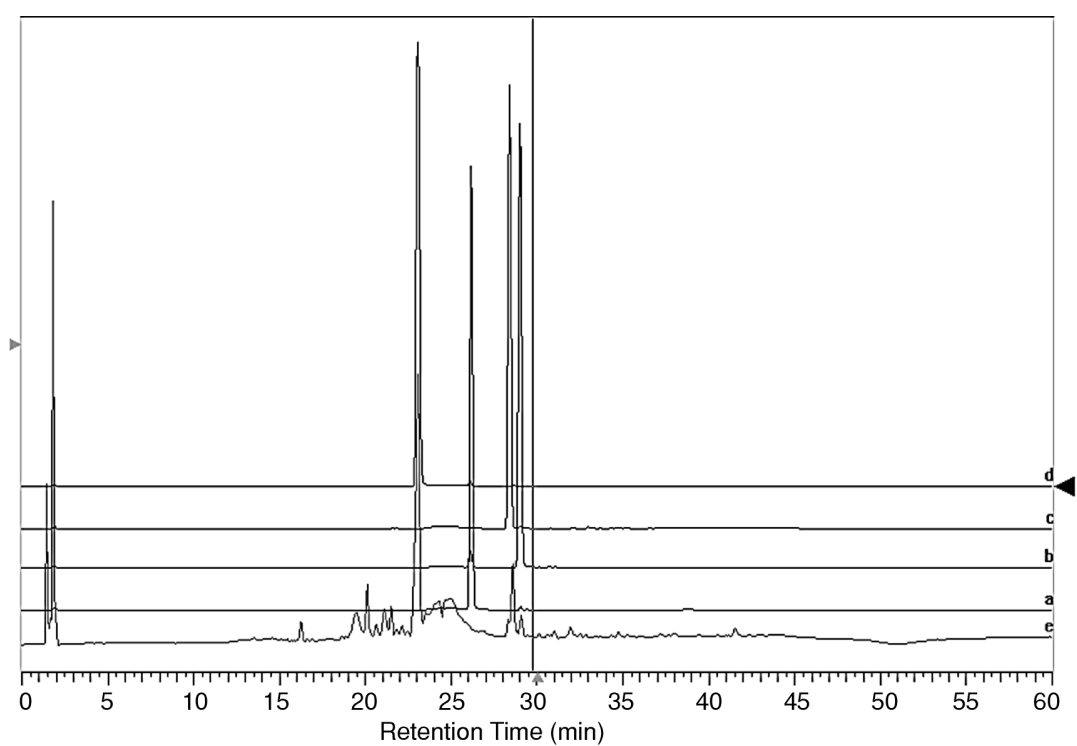

Figure 4. Chromatographic analysis of $O$. spinosa methanolic leaf extract (e). The chromatogram shows the presence of kaempferol (b), apigenin (c) and myricetin (d) but not quercetin (a)

\section{Hot-plate test and tail-flick tests}

A significant increase in latency time in hotplate was obtained after $30 \mathrm{~min}$ and $150 \mathrm{~min}$ of the treatment with $O$. spinosa extracts (300 and $600 \mathrm{mg} / \mathrm{kg}$ ) (Fig. 3A). The antinociceptive effect of the tested doses of the extract was more pronounced at $30 \mathrm{~min}$ compared to $150 \mathrm{~min}$. In tail-

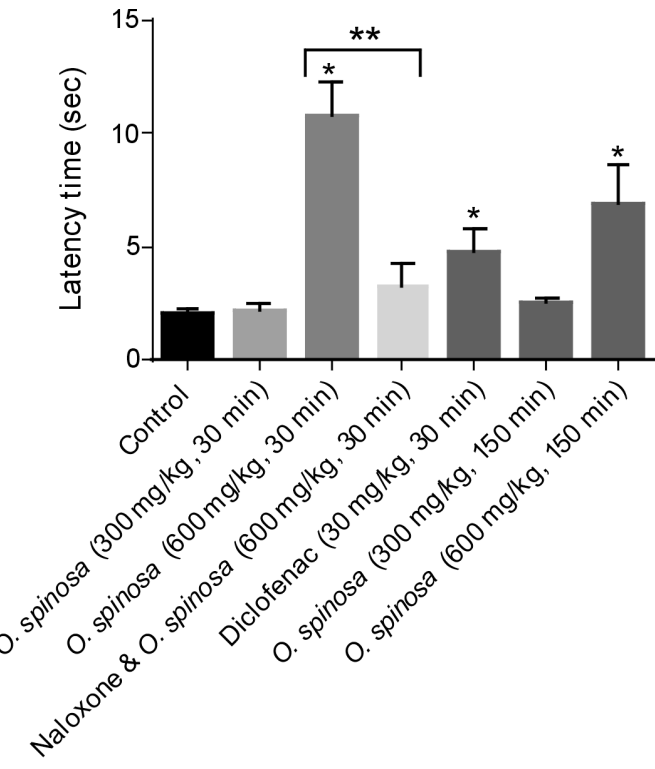

(B) 
flick test, only the high dose of $O$. spinosa $(600$ $\mathrm{mg} / \mathrm{kg}$ ) increased latency time after $30 \mathrm{~min}$ and 150 min (Fig. 3B). Naloxone antagonized the effect of $O$. spinosa extract in both; hot plate and tail flick tests (Figs. 2, 3).

\section{Qualitative analysis of phytochemicals in $O$. spin- osa}

Phytochemical screening confirmed the presence of phenolics, saponins, flavonoids, and terpenoids. Alkaloids, sterols, and anthraquinone glycosides were absent in the extracts.

\section{HPLC analysis of $O$. spinosa methanolic leaf extract}

The chromatograms show the presence of kaempferol, apigenin and myricetin but not quercetin (Fig. 4).

\section{DISCUSSION AND CONCLUSION}

In our study, the administration of $300 \mathrm{mg} / \mathrm{kg}$ and $600 \mathrm{mg} / \mathrm{kg}$ dose of $O$. spinosa extract produced $90.1 \%$ and $94.5 \%$ inhibition of abdominal cramps, respectively while diclofenac sodium $(30 \mathrm{mg} / \mathrm{kg})$ produced only $23.6 \%$ inhibition. Similar results were obtained by Bolle et al. (9) in which the root extract of $O$. spinosa reduced writhing response to phenylquinone when the extract was administered i.p but not orally and in which the extract was more effective than the standard drug.

According to Northover (10), an antinociceptive effect in the abdominal contraction tests (writhing test) cannot easily be distinguished from an anti-inflammatory action. In our study, O. spinosa extract inhibited abdominal cramps efficiently. Previous studies have reported the inflammatory activity of $O$. spinosa ethanolic root extract in vivo using carragenan-induced inflammatory model (9) and in vitro by inhibiting the cytoplasmic phospholipase $A_{2}$ enzyme (11). Cytoplasmic phospholipase $A_{2}$ catalyzes the release of a fatty acid at the $\mathrm{sn}_{2}$-position of membrane phospholipids which leads to the formation of lysophospholipid and arachidonic acid; the precursor for eicosanoids (11). In fact, eicosanoid biosynthesis is highly regulated and depends upon the activation of phospholipases $\mathrm{A}_{2}$ and the subsequent liberation of arachidonic acid, sequestered within the membrane phospholipids (12). Phospholipase $\mathrm{A}_{2}$ inhibitory activity may explain, at least partially, the antinociceptive action of $O$. spinosa in writhing test in our study.

In the present investigation, $O$. spinosa inhibited significantly paw licking in early and late phases of formalin test. Percentage inhibition in the early phase was $54.9 \%, 63.1 \%$, and $50.5 \%$ for low dose of $O$. spinosa $(300 \mathrm{mg} / \mathrm{kg})$, high dose $(600 \mathrm{mg} / \mathrm{kg})$ and diclofenac sodium $(30 \mathrm{mg} / \mathrm{kg})$, respectively while the inhibition was $81.0 \%, 85.3 \%$ and $50.5 \%$ for the three treatments, respectively. Therefore, the inhibitory effect of $O$. spinosa extract was more pronounced in the late phase of formalin test. The lowest dose tested $(300 \mathrm{mg} / \mathrm{kg})$ of $O$. spinosa extract was more efficient than $30 \mathrm{mg} / \mathrm{kg}$ diclofenac sodium in late phase of formalin test in decreasing paw licking.

The effect of $O$. spinosa was not abrogated by glibenclamide, naloxone or atropine. This indicates that the action of $O$. spinosa is not mediated by ATP-sensitive $\mathrm{K}^{+}$channel, opioid or muscarinic receptors. To our best knowledge, this is the first report of antinociceptive action of $O$. spinosa in formalin test.

A significant increase in latency time in hotplate was obtained after $30 \mathrm{~min}$ and $150 \mathrm{~min}$ of the treatment with $O$. spinosa extracts. The antinociceptive effect of the tested doses of the extract was more pronounced at $30 \mathrm{~min}$ compared to $150 \mathrm{~min}$. Contrary to our results, the administration of $O$. spinosa methanolic root extract orally or i.p produced no significant difference in reaction time in a hot-plate test in mice (9). This can be explained by the presence of different phytochemicals in roots and leaves of this plant which differ in their biological activities.

In our work, naloxone abolished O. spinosa effect after $30 \mathrm{~min}$ in hot-plate test (Fig. 3A). According to Abid and Khan (13), the hot-plate test is adequate for testing analgesics that act centrally but not peripherally. Therefore, it is expected that $O$. spinosa acts centrally. Even though, the possibility exists that this plant may act also peripherally as it gave positive results in writhing test.

In tail-flick test, only the high dose of $O$. spinosa $(600 \mathrm{mg} / \mathrm{kg})$ increased latency time after $30 \mathrm{~min}$ and $150 \mathrm{~min}$ (Fig. 3B). According to Yllmaz et al. (4), aqueous extract of $O$. spinosa aerial parts showed analgesic activity higher than aspirin in the tail-flick test. In our study naloxone abolished $O$. spinosa effect after $30 \mathrm{~min}$ in tail-flick test (Fig. 3B). Up to our best knowledge, this is the first report that $O$. spinosa may interact with the opioid receptor in thermal pain models.

Extensive phytochemical analyses of $O$. spinosa roots were performed while those of the leaves are scarce. Interestingly, ononetin, a deoxybenzoin isolated from the roots of $O$. spinosa inhibited transient receptor potential melastatin-3 (TRPM3) 
which is a non-selective calcium permeable channel (14). It is well established that TRPM3 blockade attenuates thermal nociception in vivo (14). Recently, it was demonstrated that activation of opioid receptors in mouse paw reduces the pain caused by TRPM3 protein activation (15). Further research is needed to find out if ononetin or other structurally related TRPM3 blockers are present in the aerial parts of $O$. spinosa and whether opioid receptor activation by $O$. spinosa blocks TRPM3 channels.

The present study demonstrated that $O$. spinosa methanolic leaf extract exerts analgesic effects in chemical and thermal pain models in mice. Long term toxicological studies of this plant are needed to ensure its safety since only a short-term study failed to demonstrate any toxic effects with doses up to $2 \mathrm{~g} / \mathrm{kg}$ (7). Our findings showed that interaction with the opioid receptor is a possible mechanism underlying the thermal antinociceptive action of $O$. spinosa leaf extract. Phytochemical studies are needed for the isolation of TRPM3 blockers from O. spinosa aerial parts.

\section{Acknowledgments}

The authors thank Prof. Barakat E. AbuIrmaileh at the University of Jordan for plant authentication. This work was published with the support of Al-Ahliyya Amman University.

\section{Conflicts of interest}

The authors declare no conflict of interest.

\section{REFERENCES}

1. Al-Eisawi D.M.: Field Guide to Wild Flowers of Jordan and Neighbouring Countries 1st ed. Jordan Press Foundation “Al Rai”, pp. 269, Amman 1998.

2. Fayyazi N., Naghibi F., Keramatian B., Taheri S.: Magnt. Research Report 22, 69 (2014).

3. Shaker K.H., Dockendorff K., Bernhardt M., Seifert K.: Z. Naturforsch. B 591, 124 (2004).

4. Yılmaz B.S., Ozbek H., Citoğlu G.S., Uğra s S., Bayram I. et al.: Phytother. Res. 20, 500 (2006).

5. Ergene Öz B., Saltan İşcan G., Küpeli Akkol E., Süntar İ., Bahadır Acıkara Ö.: J. Ethnopharmacol. 211, 384 (2018).

6. Al-Khalil S.: Int. J. Pharmacogn. 334, 317 (1998).

7. Rexhepi B., Mustafa B., Hajdari A., RushidiRexhepi J., Quave C.L. et al.: Genet. Resour. Crop. Evol. 607, 2055 (2013).

8. Vimalkumar C.S., Hosagaudar V.B., Suja S.R., Vilash V., Krishnakumar N.M., Latha P.G.: J. Pharmacogn. Phytochem. 3, 69 (2014).

9. Bolle P., Faccendini P., Bello U., Panzironi C., Tita B.: Pharmacol. Res. 27, 27 (1993).

10. Northover B.J.: J. Path. Bact. 87, 395 (1964).

11. Arnold E., Benz T., Zapp C., Wink M.: Molecules 20, 15033 (2015).

12. Allard-Chamard H., Dufort P., Haroun S., de Brum-Fernandes A.J.: Prostaglandins Leukot. Essent. Fatty Acids. 90, 117 (2014).

13. Abid M., Khan N.A.: Int. J. Pharma. Res. Health Sci. 55, 1891 (2017).

14. Straub I., Krügel U., Mohr F., Teichert J., Rizun O. et al.: Mol. Pharmacol. 84, 736 (2013).

15. Dembla S., Behrendt M., Mohr F., Goecke C., Sondermann J. et al.: Elife 6, e26280 (2017).

Received: 11.08. 2018 